\begin{tabular}{|c|c|c|}
\hline 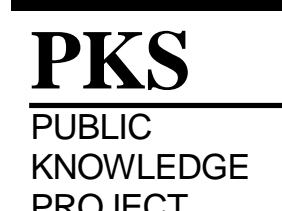 & $\begin{array}{c}\text { REVISTA DE GEOGRAFIA } \\
\text { (RECIFE) } \\
\text { htto://www.revista.ufe.br/revistageografia }\end{array}$ & 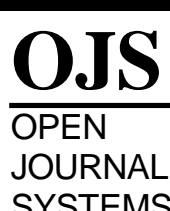 \\
\hline
\end{tabular}

\title{
ACESSIBILIDADE E O EFEITO BARREIRA NA PERIFERIA DE CIDADES MÉDIAS
}

\author{
Antonio Henrique Bernardes ${ }^{1}$; Marcos Timóteo Rodrigues Souza ${ }^{2}$ \\ ${ }^{1}$ Professor do Programa de Pós-graduação em Geografia (mestrado) e do Departamento de Geografia da \\ Universidade Federal Flumiense (UFF), Campos dos Goytacazes-RJ. Email: \\ antonio_h_bernardes@yahoo.com.br \\ ${ }^{2}$ Pesquisador Pós-Doutorando do Programa de Pós-graduação em Geografia (mestrado) da Universidade \\ Federal Flumiense (UFF), Campos dos Goytacazes-RJ. Email: marcossousa91630@gmail.com
}

Artigo recebido em 27/06/2015 e aceito em 30/04/2017

\begin{abstract}
RESUMO:
A acessibilidade e a mobilidade são conceitos associados. A primeira pode ser considerada como condição e a segunda como atributo da produção do espaço. Ambos conceitos fundamentam aquele de efeito barreira, ou seja, que indicam a separação ou o rompimento, uma descontinuidade na estrutura urbana provocada pelo sistema de transporte ou que vai influenciá-lo diretamente. Esse fenômeno nas cidades médias possui suas particularidades, dentre as quais destacamos a ocupação do sítio e a estruturação da malha viária. Para tanto, tomamos como referência os estudos das periferias de baixa renda de seis cidades médias - cinco no Estado de São Paulo: Presidente Prudente, Marília, São José do Rio Preto, Ribeirão Preto e São Carlos - e uma no Estado do Paraná Londrina.
\end{abstract}

Palavras-chaves: mobilidade, acessibilidade, efeito barreira, periferia, cidades médias.

\section{THE ACESSIBILITY AND COMMUNITY SEVERANCE IN LOW INCOME NEIGHBORHOOD OF THE MEDIUM SIZED CITIES}

\begin{abstract}
:
Accessibility and mobility are associated concepts. The first may be considered as a condition and the second as an attribute of the space production. Both concepts underlying the one of community severance, in other words which indicates the separation or the rupture, a discontinuity in the urban structure caused by the transport system or that will influence directly in it. This phenomenon in medium towns has the same particularities, among which we highlight the local occupation and the structure of the road network. There unto, we take as reference the study of the low income neighborhood of six medium sized cities - five in São Paulo state: Presidente Prudente, Marília, São José do Rio Preto, Ribeirão Preto and São Carlos - and one in Paraná state Londrina.
\end{abstract}

Key-words: mobility, acessibility, community severance, low income neighborhood, medium sized cities. 


\section{INTRODUÇÃO}

A acessibilidade e a mobilidade são conceitos indissociáveis (DEL RIO, 1990; FERRAZ, 1990; LYNCH, 1997; MOUETTE, 1998). A relação entre a acessibilidade - que é a condição pela qual ocorrem as interações espaciais para o consumo, o lazer e o trabalho e é um dos atributos do espaço, acessível ou inacessível - e a mobilidade - influenciada pela acessibilidade -, é predicado daquilo ou de quem se transporta. Considerando a acessibilidade e a mobilidade como um dos processos para produção do espaço, enquanto certo complexo constituído por múltiplas ações, interesses e representações, ela é uma das muitas abordagens possíveis a compor o amplo temário de estudos acerca do espaço urbano.

A acessibilidade é uma das variáveis para se aferir a qualidade do transporte nas cidades - isso implica que devemos considerar os custos para os deslocamentos, o tempo total envolvido no sistema de transporte, tipos, condições e conforto dos veículos, distância etc. na medida em ela se relaciona com o uso e ocupação do uso do solo, estrutura e forma urbana. A estrutura da malha viária está diretamente relacionada ao modo de estruturação histórica e socioeconômica das cidades e o conteúdo social que fundamenta a estrutura urbana é o mesmo que qualifica suas formas.

O efeito barreira comparece como um dos elementos que compõe a forma urbana e possui repercussões diretas sobre o grau de acessibilidade que possuem os citadinos (MOUETTE, 1998; RODRIGUES, 2006; SANCHES, 1996; VASCONCELOS, 2000). Ele pode ser entendido como uma descontinuidade na estrutura urbana que influencia o sistema de transporte e pode ocasionar a interrupção no tráfego devido a decorrências de fenômenos naturais ou obras de engenharia, como rodovias ou ferrovias. Esse fenômeno pode ser associado ao desenvolvimento dos bairros dormitórios nas periferias das cidades e seu acesso restritivo. Nesse sentido, o efeito barreira além de se relacionar com forma urbana, também está vinculado às condições naturais do sítio e, sobretudo, a produção do espaço urbano. Em conjunto, esses elementos são a base da estrutura espacial e determinam a circulação e o movimento dos citadinos no espaço urbano.

Considerando uma perspectiva que atribui relevo as estruturas e as formas urbanas, o efeito barreira se perfaz quando os citadinos estão localizados além da linha ou faixa que exerce o papel de barreira em relação às áreas que exercem maior centralidade. Isso pode ocorrer devido a concentração de infraestrutura, equipamentos, serviços e da própria vida urbana. 
A mobilidade e a acessibilidade são uns dos conceitos fundamentais para se entender a estruturação do espaço urbano, quando o consideramos diretamente associados ao arranjo territorial dos usos, conteúdos e funções do espaço urbano e pelas políticas de transporte (MIHESSEN, 2013; ULIAN, 2015). Corteletti (2015) não trata exatamente a condição do efeito barreira, mas, podemos entender que essas condições - transporte urbano, mobilidade e acessibilidade - podem acentuar ou atenuar as barreiras físicas e sociais ocasionados por características da morfologia urbana, assim como, as desigualdades socioespaciais. A relevância está em um dos âmbitos de uma pesquisa que visa, por meio da análise do consumo, entender as intrínsecas relações entre as lógicas econômicas de estruturação e o conjunto das práticas espaciais que elas condicionam e que é, ao mesmo tempo, um dos planos de suas redefinições (SPOSITO, 2011).

Desse modo, tomando como base os estudos corroborados no Projeto Temático "Lógicas econômicas e práticas espaciais contemporâneas: cidades médias e consumo"1 foram desenvolvidas algumas análises para identificar e analisar os bairros periféricos e a sua relação com a área central de seis cidades médias, especificamente: cinco no Estado de São Paulo - Presidente Prudente, Marília, São José do Rio Preto, Ribeirão Preto e São Carlos -; e, uma no Estado do Paraná - Londrina. Visou-se entender como a forma urbana, uso do solo, sistema viário e os itinerários dos ônibus propiciaram um efeito barreira nos bairros das cidades médias consideradas. Contudo, porque investigar o efeito barreira em cidades médias e quais as suas principais diferenças para as cidades grandes pequenas?

O efeito barreira em cidades médias é bem notório devido à estruturação de muitas cidades brasileiras. Especificamente na pesquisa supracitada, as cidades estudadas possuem uma população entre 200 a 600 mil habitantes e uma área entre 300 a 1.500 quilômetros quadrados. Considerando esses elementos, o centro das cidades e as áreas periféricas apresentam algumas descontinuidades. Os tecidos urbanos muitas vezes são marcados por barreiras constituídas por pontes, rios, viadutos, reservas de valor para especulação imobiliária e o relevo do município. Nessas cidades, as linhas de ônibus circulam entre os bairros, normalmente, percorrem itinerários radiais e diametrais, em que os veículos circulam em média 10 quilômetros por dia. Portanto, as aparições das barreiras físicas e sociais são marcantes, proporcionando um efeito na mobilidade.

\footnotetext{
${ }^{1}$ Ambos os autores desse manuscrito são pesquisadores associados ao Projeto Temático "Lógicas econômicas e práticas espaciais contemporâneas: cidades médias e consumo" fomentado pela FAPESP (Fundação de Amparo à Pesquisa do Estado de São Paulo). 
Em contraponto, podemos afirmar que em cidades de grande porte há uma maior quantidade de barreiras, assim como, o número de habitantes e de usuários do transporte coletivo são maiores que cidades médias. Os itinerários dos ônibus são diversificados e há mais de um centro. $\mathrm{O}$ efeito barreira em grandes cidades não será pontuado por um ou dois elementos marcantes na paisagem como são nas cidades médias, pois haverá diversas barreiras em vários bairros e centros. Por sua vez, em cidades pequenas quase não há uma utilização efetiva do transporte coletivo, a população está normalmente abaixo dos 100 mil habitantes e as barreiras físicas não se tornam obstáculos contundentes que promovam certa imobilidade urbana.

Desse modo, considerando a especificidade de estruturação das cidades médias, primeiramente abordaremos a metodologia que amparou as atividades de pesquisa desse trabalho para em seguida se discutir o conceito de acessibilidade como um indicativo da mobilidade dos citadinos e, depois, o efeito barreira como um dos conceitos que apontam para uma espécie de disfunção urbana, notadamente, quando interrompe os deslocamentos e movimentos na cidade. Quando relacionamos a acessibilidade e a mobilidade ao efeito barreira notamos que a produção do espaço urbano é desigual e corrobora em processos de segregação socioespacial, ao menos para as periferias de baixa renda nas cidades médias consideradas, que serão objetos de investigação e discussão no último tópico desse texto.

\section{METODOLOGIA DE PESQUISA}

Os pressupostos para o desenvolvimento metodológico se baseou na análise da mobilidade populacional de moradores de bairros periféricos e de baixa renda em seis cidades médias, especificamente: cinco no Estado de São Paulo - Presidente Prudente, Marília, São José do Rio Preto, Ribeirão Preto e São Carlos -; e, uma no Estado do Paraná - Londrina.

Antes de tudo, se julgou necessário entender a distribuição da rede de transportes e a estruturação viária destas cidades, interpretação que nos auxiliou a entender o "desenho urbano" e os possíveis problemas de acessibilidade. Considerou-se os movimentos pendulares dos bairros residenciais das periferias às áreas centrais de serviços e da acessibilidade urbana para análise, pois a valorização de áreas centrais se dá pelo movimento pendular de trabalhadores e estudantes que se deslocam de áreas periféricas à procura de melhores formas de consumo em áreas centrais. 
De modo geral, os trabalhos de campo foram realizados coletivamente, em conjunto com os pesquisadores do grupo vinculados ao Projeto Temático "Lógicas econômicas e práticas espaciais contemporâneas: cidades médias e consumo" e, por vezes, por meio de incursões individuais, voltadas mais diretamente à observação sistemática dos problemas quanto a mobilidade urbana, do transporte coletivo e o efeito barreira. As incursões na cidade de Presidente Prudente, assim como suas respectivas análises, foram realizadas em várias datas, pois, o acesso era facilitado. Já os trabalhos de campo nas demais cidades foram realizados nas seguintes datas a saber: de 31/10/2013 à 03/11/2013 nas cidades de Marília e São Carlos; de 10/07/2014 à 13/07/2014 na cidade de São Carlos; de 20/07/2014 à 23/07/2014 na cidade de Londrina; de 01/08/2014 à 03/08/2014 na cidade de Ribeirão Preto; de 05/10/2014 à 08/10/2014 na cidade de São José do Rio Preto; de 22/11/2014 à 23/11/2014 na cidade de São José do Rio Preto.

Os dados e informações foram coletados, por meio das visitas às instituições públicas como: Prefeituras Municipais, Secretarias Municipais de Transporte, Secretarias de Planejamento Urbano e Secretarias de Habitação, além de entrevistas com citadinos e com agentes bem informados - bem informados são considerados os empresários do setor de transporte ou com algum secretário ou profissional das Secretarias de Transporte ou outros responsáveis pela gestão deste setor - nos centros das cidades. Somaram-se, ainda os trabalhos de organização, tabulação e representação gráfica e cartográfica efetuada posteriormente em gabinete.

Em pesquisas prévias sobre as cidades estudadas e por meio de trabalhos de campo foram selecionados seis bairros da periferia, um para cada cidade. Eles possuem como característica em comum serem ocupados por segmentos sociais de baixa renda, para tanto ainda se considerou a formação e produção do espaço urbano das cidades e aqueles bairros mais afastados do centro e que pelas barreiras físicas poderiam dificultar a acessibilidade de seus moradores. As análises tinham como objetivo entender a acessibilidade às áreas centrais das cidades, os efeitos barreiras e a mobilidade dos moradores de áreas periféricas de baixa renda. Com aspecto qualitativo, buscamos visitar a associação de moradores em cada um dos bairros estudados, sendo os bairros: em Presidente Prudente o Bairro Ana Jacinta; em Marília o Bairro Nova Marília; em São Carlos o Bairro Cidade Aracy; em Londrina o Bairro Conjunto Newton Guimarães; em São José do Rio Preto o Bairro Eldorado; e, em Ribeirão Preto o Bairro Florestan Fernandes. 


\section{A ACESSIBILIDADE E A MOBILIDADE NO ESPAÇO URBANO}

O conceito de acessibilidade não pode ser confundido com o de mobilidade, embora estejam associados.

Na visão tradicional, segundo Cunha (2002), a mobilidade é entendida como os movimentos das pessoas dentro das cidades ou entre elas com determinadas finalidades, é indicada pela relação de viagens por habitante em dado período de tempo. A mobilidade pendular é habitualmente utilizada para designar os movimentos cotidianos das populações, é uma questão funcional que resulta da organização do território e da não coincidência entre local de residência e os locais de trabalho, estudo e lazer. As análises da mobilidade urbana se fazem necessárias devido ao entendimento da dinâmica intraurbana e intrarregional, nesse sentido a "pendularidade" é extremamente relevante para a compreensão dos processos de espraiamento urbano e redistribuição espacial da população.

Pero e Mihessen (2013) entendem a mobilidade de uma maneira sustentável, desta forma, há uma contraposição à visão tradicional de circulação no meio urbano. Os autores fazem uma crítica à visão tradicional, pois não entendem que a mobilidade seja apenas a habilidade de movimentar-se no espaço apenas em decorrência de condições físicas e econômicas. Na visão sustentável, a mobilidade é o resultado de um conjunto de políticas de transporte e circulação que visa proporcionar o acesso amplo e democrático ao espaço urbano. Nesta perspectiva há uma ênfase na priorização dos modos de transporte coletivo e nãomotorizado.

Cardoso (2013) diz que a mobilidade é a capacidade do citadino de se deslocar espacialmente e envolve dois componentes: a) desempenho do sistema de transporte e a sua capacidade de interligar dois locais distintos; b) as características do próprio indivíduo, associadas ao seu grau de inserção perante o sistema de transporte. Para Cardoso (2013) a acessibilidade associa-se à capacidade de alcançar um determinado lugar, sendo comumente mensurada pelo atributo de tempo de viagem, enquanto que mobilidade, medida pelo número de viagens/dia/pessoa.

Já a acessibilidade está relacionada com a oportunidade que certo citadino tem de realizar uma atividade singular, alcançando um determinado destino. Segundo Vasconcellos (2000), o conceito de acessibilidade possui muitas definições, fundamentadas em diferentes teorias. De uma forma geral, é definido como sendo uma medida de esforço para se transpor certa separação físico-territorial, caracterizada pelas oportunidades apresentadas ao citadino 
ou grupos sociais para que possam exercer suas atividades pelo uso dos sistemas de transportes. A acessibilidade torna possível o acesso dos citadinos aos locais de emprego, lazer, estudo, equipamentos públicos etc. e é função tanto do uso do solo, como das características do sistema de transporte, o período do dia que ocorrem e o objetivo da viagem.

Ordinariamente, a acessibilidade é definida a partir da facilidade em se atingir os destinos desejados, sendo, portanto, a medida mais direta dos efeitos de um sistema de transporte, a qual pode ser inferida a partir do número e da natureza dos destinos que podem ser alcançados por um citadino ou, indiretamente, a medida dada pela densidade das linhas de transporte público.

A oportunidade de chegar a um destino pode ser expressa matematicamente pelo índice de acessibilidade, associado a parâmetros como custo e tempo de viagem (SANTANNA, 1995). Contudo, não devemos restringi-la somente a uma relação matemática, pois ela pode refletir e reforçar estruturas sociais e espaciais que historicamente são marcadas pela desigualdade social e ao acesso às condições de deslocamento no espaço urbano. Esses fenômenos podem ser associados a formação socioespacial de muitas cidades brasileiras, uma vez que eles possuem relação direta com a disponibilidade ou escassez para o deslocamento e, como tal, se articulam diretamente com a estruturação das cidades.

A falta ou escassez das condições de acessibilidade é aguda entre os citadinos que estão em grupos sociais que possuem as piores condições econômicas, os quais, em sua maioria, coincidem com aqueles que habitam as áreas mais afastadas das áreas que exercem significativa centralidade urbana. Expressam-se espacialmente as relações sociais desiguais nas cidades, normalmente, essas áreas afastadas estão menos equipadas por infraestrutura, meios de consumo coletivo e, consequentemente, são menos acessíveis. Sousa e Sposito (2013) afirmam que em um local de alta acessibilidade é mais atrativo do que um com baixa. Portanto, a acessibilidade influencia a valorização dos imóveis e dos setores da cidade e eventuais mudanças quanto à acessibilidade afetam o preço dessas localidades. De forma genérica, um dos modos de promover o desenvolvimento urbano e social de certa área é melhorar sua acessibilidade, o que terá repercussões na sua valorização econômica.

Nesse sentido, a acessibilidade é um indicador apropriado para avaliar a qualidade do transporte nas cidades, pois essa é a função tanto do padrão do uso do solo como das características dos sistemas de transporte (SANCHES, 1996). O fator distância - que pode revelar ou induzir separação espacial e, às vezes, segregação socioespacial - perde importância à medida que, aliado a uma melhora de acessibilidade, se promova maior 
adequação no sistema de transporte, pois isso acarreta a diminuição do tempo de viagem e maior conforto.

A acessibilidade também pode ser analisada mediante a abordagem crítica dos custos envolvidos nos deslocamentos, relacionados ao tempo total envolvido no sistema de transporte, ou seja, a caminhada até o ponto ou terminal de transporte, o tempo de espera, o tempo de viagem e o tempo de transferência. Ademais, a acessibilidade varia conforme os veículos utilizados, em outras palavras, conforme os segmentos sociais se manifestam sob a forma de distinção entre a acessibilidade de quem depende de transporte coletivo e de quem possui transporte individual.

Em suma, a circulação urbana indica certas dinâmicas que podem atenuar ou acentuar desigualdades socioespaciais. Sua relevância está no âmbito de uma pesquisa que visa, por meio da análise do consumo, entender as intrínsecas relações entre as lógicas econômicas de estruturação espacial e o conjunto das práticas espaciais que elas condicionam e que é, ao mesmo tempo, um dos planos de suas redefinições.

\section{O EFEITO BARREIRA}

Segundo Mouette (1998), o termo efeito barreira é correspondente a severance, expressão inglesa que indica separação ou rompimento, ou seja, uma descontinuidade na estrutura urbana provocada pelo sistema de transporte ou que vai influenciá-lo diretamente, mesmo que não tenha origem na forma de estruturação desse sistema. Na literatura francesa, há a terminologia effect coupure, que é utilizada para denotar a barreira como uma interrupção no tráfego, mas, também, pode se referir a qualquer barreira ou impedimento ocasionado por algum elemento da paisagem decorrente de fenômenos naturais ou de obras de engenharia.

Segundo Consiglieri (1999), o termo efeito barreira (community severance), surgiu na primeira metade do século XX e se relacionava com o desenvolvimento dos bairros dormitórios nos subúrbios e a consequente extensão da jornada de trabalho, causando uma deterioração da vida social e comunitária da população afetada. Lassière (1976 apud MOUETTE, 1998) elaborou um amplo estudo sobre a avaliação dos impactos ambientais decorrentes dos transportes. Ele considerou que o efeito barreira é um fenômeno que pode decorrer da implantação de estruturas lineares principais, como uma rodovia ou uma ferrovia. Ele ainda propõe uma série de parâmetros e elementos a serem analisados, resultando na 
necessidade do conhecimento das características demográficas, do uso e ocupação do solo, bem como dos padrões de deslocamento.

Mouette (1998, p.23) amplia o conceito original e utiliza o termo efeito barreira para denotar "o conjunto de respostas perceptíveis, atitudinais e comportamentais resultantes de certas formações lineares no meio ambiente urbano". Esteves (1985 apud MOUETTE, 1998, p.28) define o fenômeno como "o estado em que os usuários de uma parte da cidade ou núcleo urbano têm seu acesso dificultado à outra parte da mesma cidade ou núcleo urbano, em virtude da existência de obstáculo, gerando problemas de compartimentação".

Podemos aferir que o efeito barreira faz parte das disfunções urbanas que, a princípio, são todos e quaisquer impedimentos ou dificuldades encontradas pelos citadinos no espaço urbano para o exercício de qualquer atividade, circulação ou permanência por deficiência estrutural ou de grandes distâncias entre localidades (RODRIGUES, 1986). Nesse sentido, é possível considerar três variáveis para a geração do efeito barreira: 1 - os elementos causadores; 2 - os elementos de influência; 3 - os impactos decorrentes. Esses efeitos têm relação direta com a forma urbana compreendida em seu sentido mais amplo, ou seja, incluindo sítio urbano e plano urbano (MOUETTE, 1998).

A essência da forma urbana é dialeticamente produzida pela relação entre dimensões políticas, econômicas e culturais da cidade. A forma urbana é perceptível a todos os citadinos, mas, quanto maior a vivência e o grau de envolvimento com o local, o nível de percepção espacial é maior, ou seja, a identificação dos problemas ocasionados pelo efeito barreira pode ser perceptível de modos e intensidades diferentes (OKAMOTO, 2002), pois ele diminui a quantidade de deslocamentos, bem como a qualidade deles. Esse fato se reflete na perda da mobilidade do citadino, que tem sua locomoção restringida, na consequente perda na acessibilidade a espaços e estabelecimentos localizados "do outro lado" da via a ser transposta (MOUETTE, 1998).

O espaço urbano e o perfil e práticas dos citadinos são alguns dos elementos que influenciam o efeito barreira que resultam das características da forma urbana e essa, por sua vez, influencia o trânsito dos citadinos e dos automóveis. Esse último possui relação direta com as vias de determinado setor da cidade, das atitudes e comportamentos dos diferentes segmentos sociais, bem como, do ambiente no qual estão inseridos.

Lynch (1997) indica que há um modo entender a forma da cidade por meio de uma legibilidade, ou seja, a qualidade visual da cidade pode ser estudada e interpretada pelo método do estudo mental da imagem. Os citadinos que habitam o ambiente afetado pelo efeito 
barreira percebem e têm sensações visuais de cor, forma e movimento, organizando um sistema de referências específicas. As vias, o desenho das ruas, os limites dos bairros, os pontos nodais, as interrelações entre os elementos, a qualidade da forma e o sentido do todo compõem a paisagem e a forma urbana. A forma e a paisagem urbana são indissociáveis da estrutura espacial da cidade.

A estrutura espacial urbana é visível na paisagem, quando considerada sua forma. $\mathrm{O}$ deslocamento dos automóveis e do transporte coletivo é executado em meio ao arranjo espacial das vias que compõem o desenho da cidade. Muitas vezes, a forma das cidades se apresenta como uma barreira aos moradores dos bairros suburbanos e periféricos, causando ou reforçando processos de segregação socioespacial. A acessibilidade do pedestre, do ciclista e dos que se deslocam por transporte coletivo está muito ligada ao entendimento da estrutura espacial, pois o território, em termos geométricos e socioeconômicos, possui uma forma, que tem relação dialética com seus conteúdos econômicos, políticos e sociais.

A forma está vinculada às condições naturais do sítio urbano e, sobretudo, ao processo de produção do espaço urbano. Eles se associam o plano urbano e o uso do solo, que são base da estrutura espacial e que determina a circulação e o movimento no espaço urbano. Considerando a dialética entre a forma e o conteúdo, aferimos que o deslocamento e o movimento - veículos, citadinos, mercadorias, ideias e símbolos - imprimem conteúdo à forma e, portanto, ao que é físico ou material, possibilitando múltiplas formas de apreensão do que é ideológico e/ou simbólico no espaço. Como afirma Del Rio (1990, p.55): "toda função social só é visível e possível através de uma forma e que é a forma que permite a existência do fato urbano".

O efeito barreira, como elemento importante na composição da forma urbana, possui repercussões diretas sobre o grau de acessibilidade que tem os citadinos localizados além da linha ou faixa que exerce o papel de barreira, em relação às áreas de maior densidade de infraestrutura, equipamentos e serviços. A acessibilidade pode ser expressa sob a forma de índices, ou seja, valores que a traduzem, mas pode ser sentida também nos comportamentos e representações sociais que se elaboram sobre uma área que esteja excluída ou segregada do conjunto da cidade.

As funções de cada setor da cidade, as formas como se articulam a outras parcelas do espaço urbano, bem como as condições que são oferecidas ou não para as interações espaciais redefinem-se conforme processos de estruturação do espaço urbano, que são a expressão de contextos locais articulados as dinâmicas de outras escalas geográficas. Quando o sistema de 
transporte coletivo e as vias de tráfego não acompanham as lógicas que orientam a estruturação, nota-se um hiato entre as demandas e as efetivas formas de circulação, podendo ocasionar segregação socioespacial em áreas afastadas ou separadas pelo efeito barreira, em relação ao conjunto do espaço urbano.

A mobilidade e a acessibilidade, conceitos fundamentais para se entender a estruturação do espaço urbano, estão diretamente condicionadas pelo arranjo territorial dos usos, conteúdos e funções do espaço urbano e pelas políticas de transporte urbano, condições essas que podem acentuar ou atenuar o efeito barreira ocasionado por características da morfologia urbana.

\section{ALGUMAS CONSIDERAÇÕES ACERCA DO EFEITO BARREIRA NA PERIFERIA DE CIDADES MÉDIAS}

Em acordo com os estudos corroborados no Projeto Temático "Lógicas econômicas e práticas espaciais contemporâneas: cidades médias e consumo" foram desenvolvidos alguns cartogramas para identificar e analisar os bairros periféricos e a sua relação com a área central de seis cidades médias, especificamente, são cinco no Estado de São Paulo - Presidente Prudente, Marília, São José do Rio Preto, Ribeirão Preto e São Carlos - e uma no Estado do Paraná - Londrina. Visou-se entender como a forma urbana, uso do solo, sistema viário e os itinerários dos ônibus propiciaram um efeito barreira nos bairros das cidades consideradas. 


\section{O efeito barreira em Marília, Estado de São Paulo}

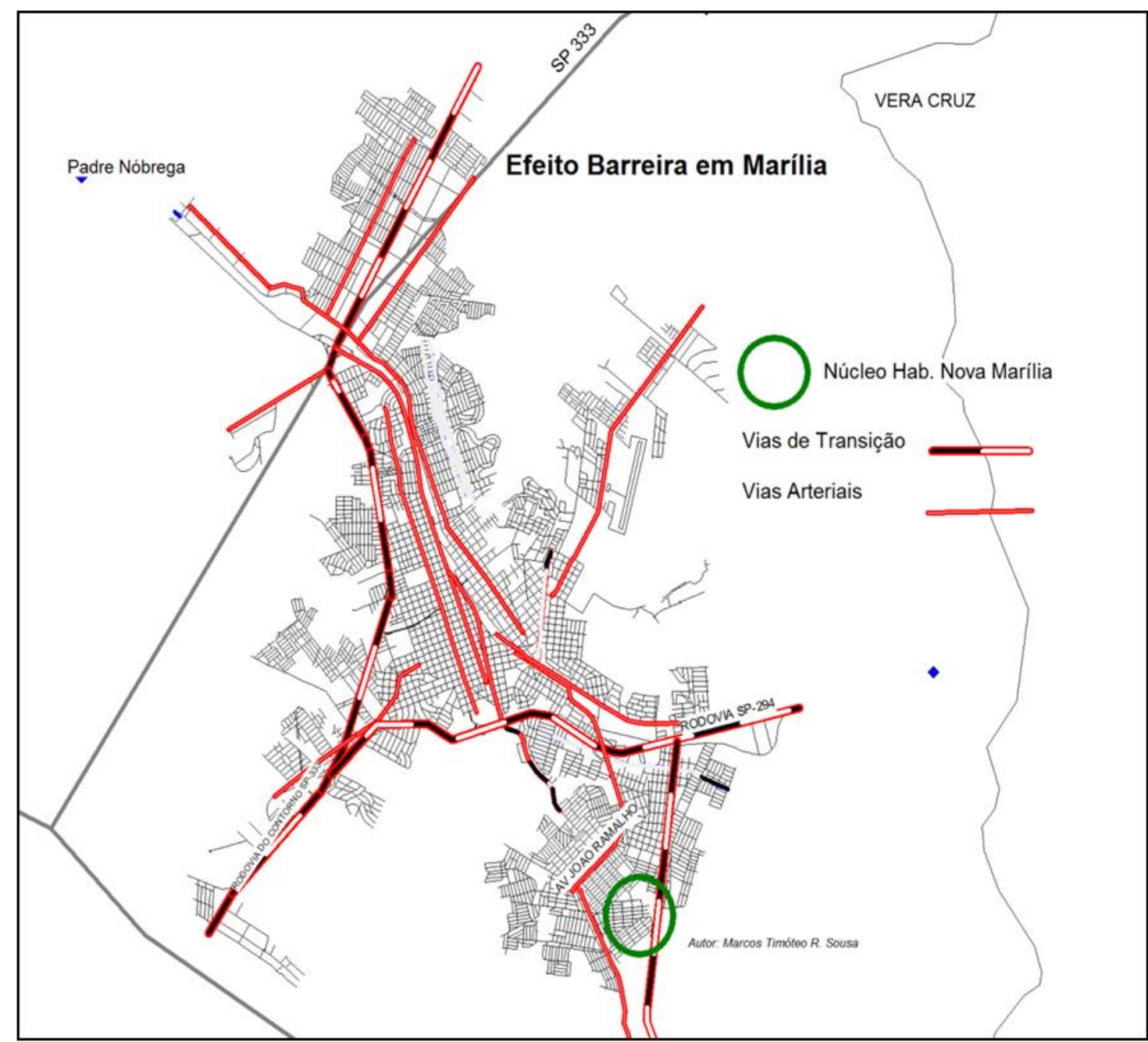

FIGURA 1: EFEITO BARREIRA NA CIDADE DE MARÍLIA, ESTADO DE SÃO PAULO, 2013.

Fonte: Pesquisa de Campo, 2013 e IBGE (2010).

Em conformidade com a Figura 1, identificamos que o Bairro Nova Marília, localizado na Zona Sul do município de Marília, possui apenas um eixo viário para a circulação de ônibus que liga o bairro ao centro da cidade. As Avenidas João Ramalho e Durval de Menezes, que são continuação uma da outra, é o principal eixo de ligação ao Terminal Urbano e aos outros bairros da cidade. A Rodovia SP 294 é a barreira que separa o bairro do restante da cidade, além desse componente há o relevo do município, pois, a oeste do Bairro há um grande desnível no terreno, acompanhado de um vazio urbano. 


\section{O efeito barreira em Presidente Prudente, Estado de São Paulo}

A seguir, pela Figura 2, podemos identificar o Bairro Ana Jacinta no município de Presidente Prudente. Nota-se que a Rodovia Júlio Budiski é a grande barreira que separa o bairro do restante da cidade. A única "porta de entrada" para o Ana Jacinta é a confluência entre as Rodovias Alberto Bonfiglioli e Júlio Budiski. No entrono da confluência entre as duas rodovias há um vazio urbano, no sentido nordeste, em direção ao centro da cidade, surge outra barreira, a Rodovia Rodovia Raposo Tavares. Todas as linhas de ônibus que adentram ao bairro cortam as rodovias Raposo Tavares e Júlio Budiski, a Avenida Manoel Goulart é o principal eixo de ligação longitudinal do bairro.

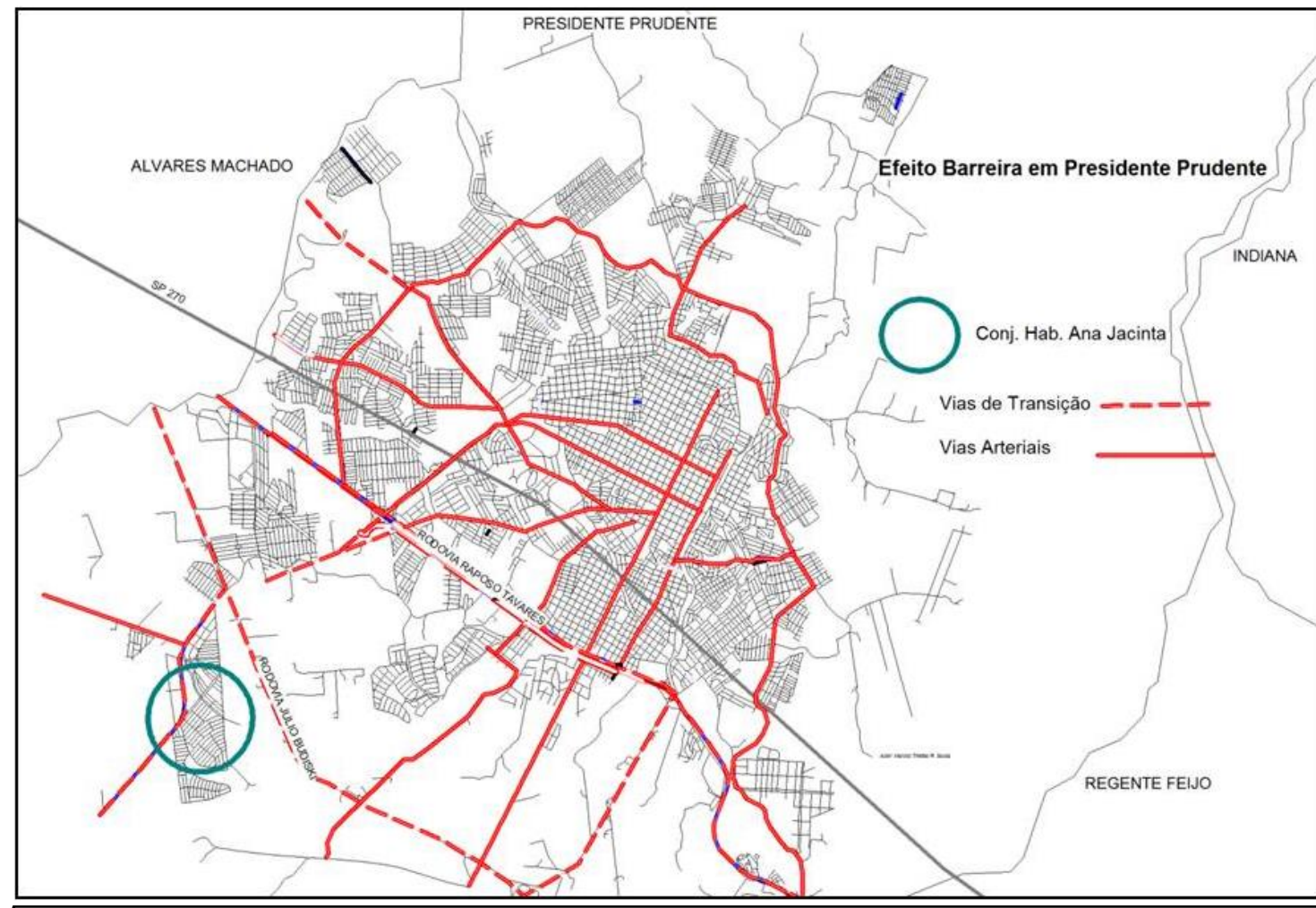

FIGURA 2: EFEITO BARREIRA NA CIDADE DE PRESIDENTE PRUDENTE, ESTADO DE SÃO PAULO, 2013.

Fonte: Pesquisa de Campo, 2013 e IBGE (2010).

\section{O efeito barreira em São José do Rio Preto, Estado de São Paulo}

A cidade de São José do Rio Preto é dividida pelo Rio Preto. Nas porções leste e oeste, em termos comparativos, a cidade tem uma morfologia bem diferente das demais. As rodovias BR 153 e a Rodovia Washington Luís cortam a cidade, no entanto, o Bairro 
Eldorado, escolhido para os estudos de efeito barreira e mobilidade, não tem as rodovias como barreira física. As Zonas Norte e Leste do município é a área periférica mais antiga da cidade, vale o destaque, em termos de efeito barreira para o rio. A formação natural do Rio Preto se transforma numa barreira física aos moradores desse bairro, como pode ser notado pela Figura 3 a seguir.

Todas as linhas de ônibus cruzam as avenidas João Bernardino Seixas Ribeiro e Delgado Pinto Toledo em direção à Avenida Monte Aprazível, principal eixo viário do bairro, que corta o a área no sentido nordeste-sudoeste. Vale lembrar que em São José de Rio Preto, como em Marília, todas as linhas de ônibus são radias, ou seja, passam pelo Terminal Central.

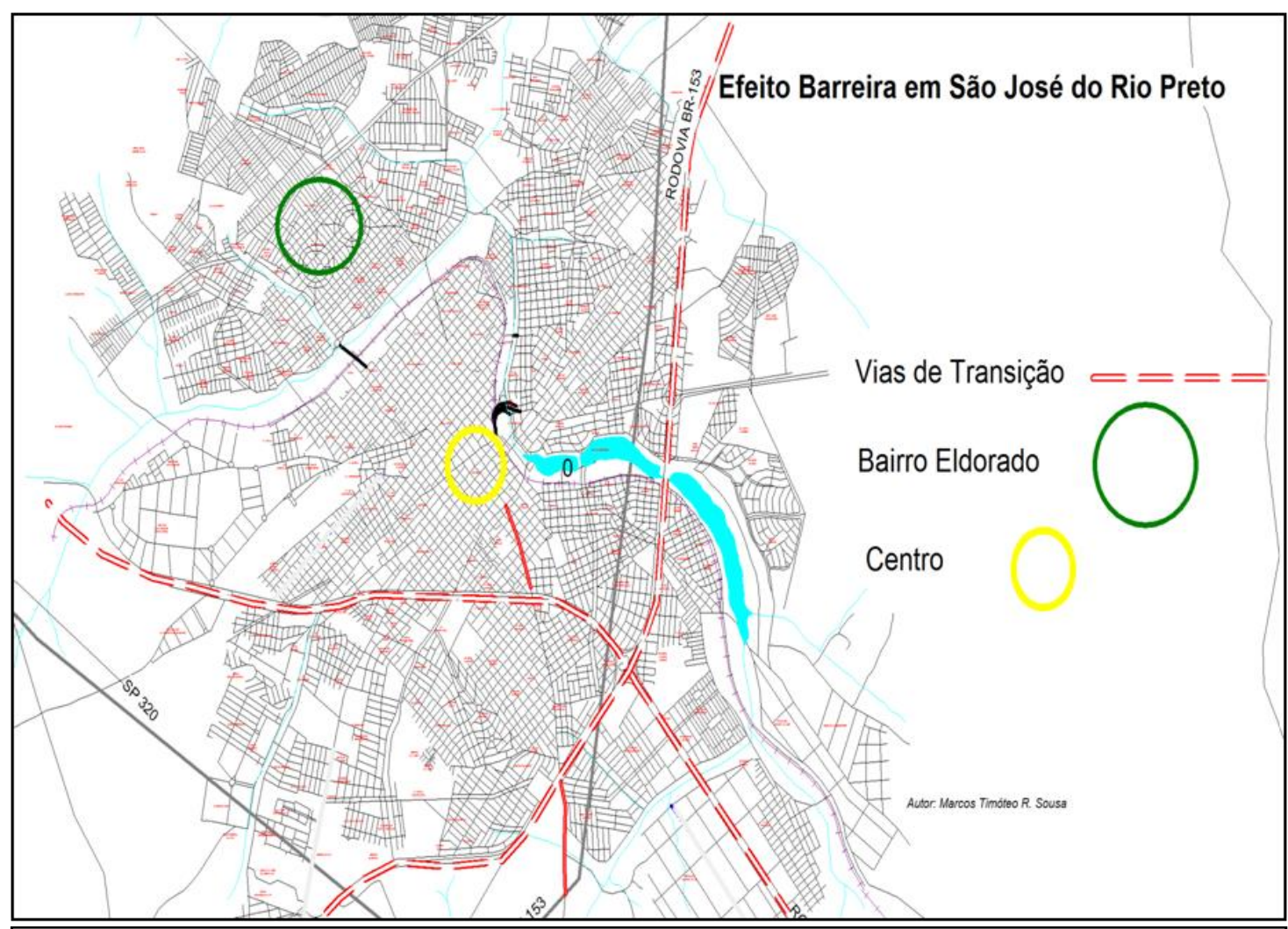

FIGURA 3: EFEITO BARREIRA NA CIDADE DE SÃO JOSÉ DO RIO PRETO, ESTADO DE SÃO PAULO, 2013. Fonte: Pesquisa de Campo, 2013 e IBGE (2010). 


\section{O efeito barreira em Ribeirão Preto, Estado de São Paulo}

O município de Ribeirão Preto possui a peculiaridade dentre aqueles estudados, pois muitos de seus bairros localizados na Zona Leste da cidade que ficam às margens da Rodovia Anhanguera e desenvolve o efeito barreira. A Figura 4 exibe o bairro Florestan Fernandes, que fica cerca de 13 quilômetros de distância do centro da cidade. A zona Leste é a área mais pobre da cidade. A avenida A é a principal via ligação entre o bairro e o centro.

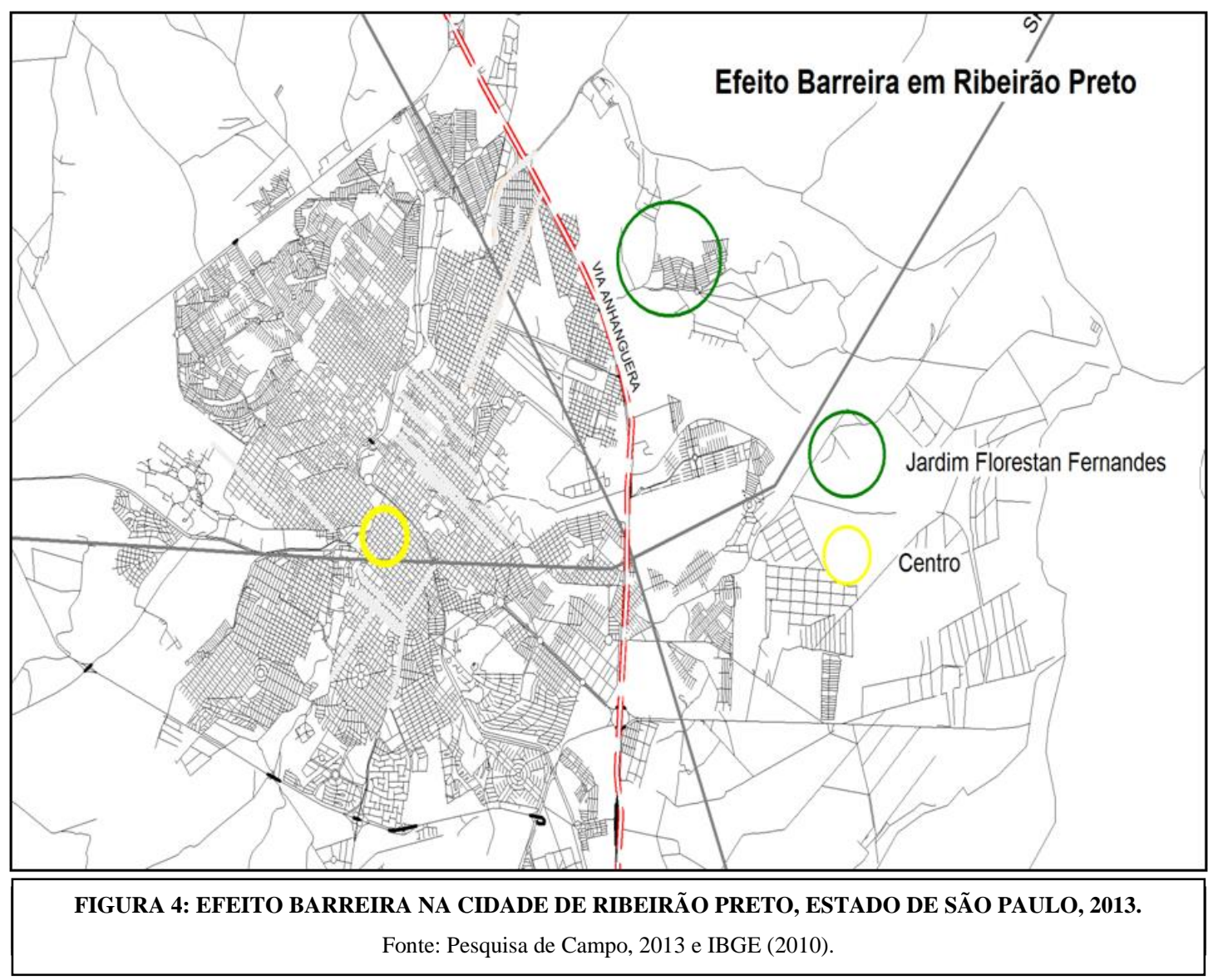

\section{O efeito barreira em São Carlos, Estado de São Paulo}

A Figura 5 vai demonstrar o efeito barreira entre o Bairro Cidade Aracy e Bairro Cruzeiro do Sul no município de São Carlos. O Bairro Cruzeiro do Sul é uma zona periférica consolidada, ou seja, um bairro mais antigo do que a Cidade Aracy, a "Serrinha do Aracy" separa as duas áreas.

Há uma barreira causada por uma serra que separa duas áreas distintas - "Serrinha do Aracy”. A ainda Figura 5 demonstra os dois bairros que estão separadas por desnível de 
relevo que contribui com a formação de uma barreira social e física. A declividade dessa área é de $3,8 \%$, os pedestres e os ônibus circulam pela via principal com muitas dificuldades. $\mathrm{O}$ Bairro Jardim Cruzeiro do Sul está 57 metros mais alto que o Bairro Jardim Aracy e possui uma melhor estrutura viária, equipamentos urbanos e proximidade ao centro. No Bairro Jardim Aracy, há grande densidade construtiva e, portanto, habitacional, o que significa que muitos citadinos têm dificuldades em acessar a área central da cidade.

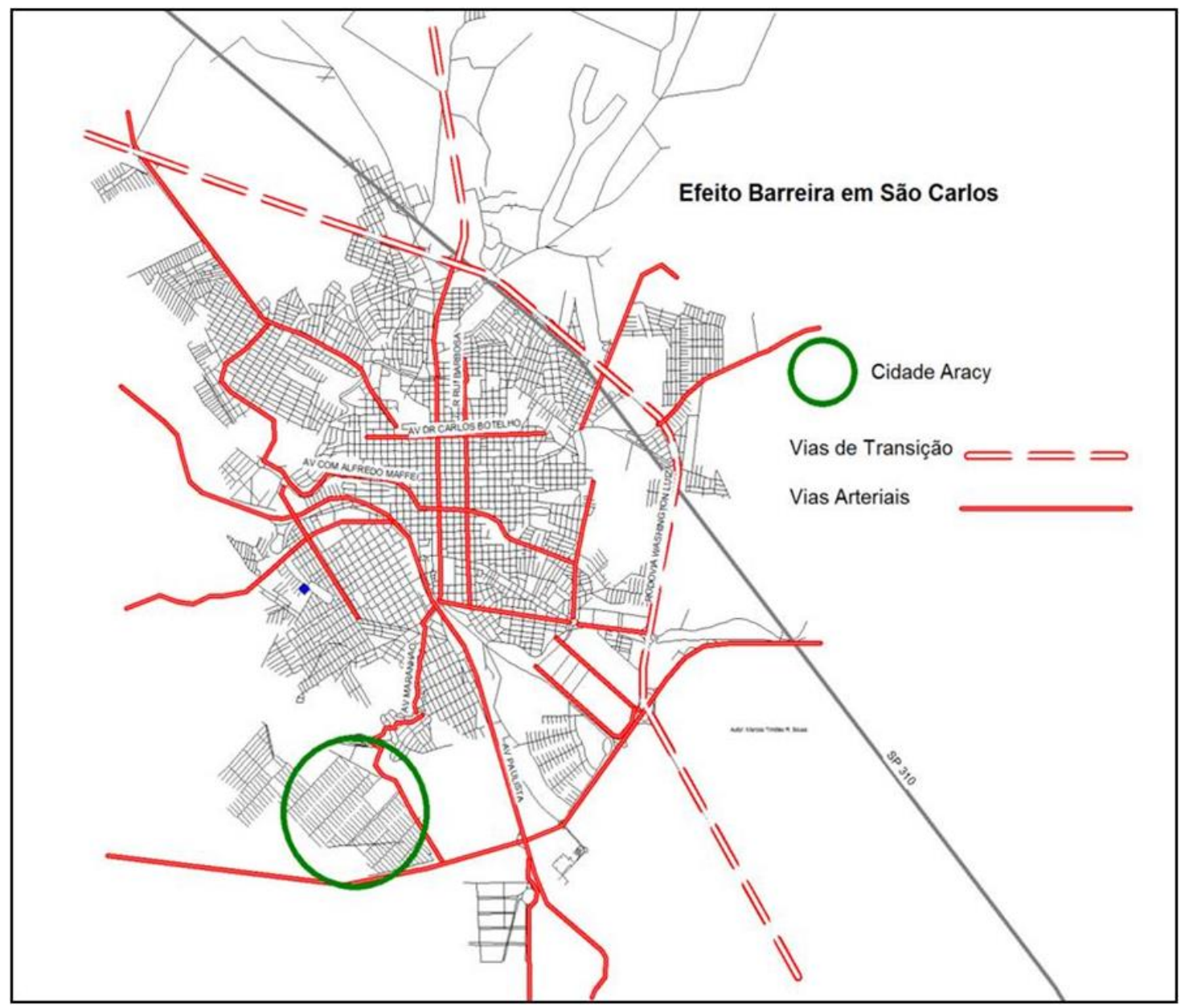

FIGURA 5: EFEITO BARREIRA NA CIDADE DE SÃO CARLOS, ESTADO DE SÃO PAULO, 2013.

Fonte: Pesquisa de Campo, 2013 e IBGE (2010). 


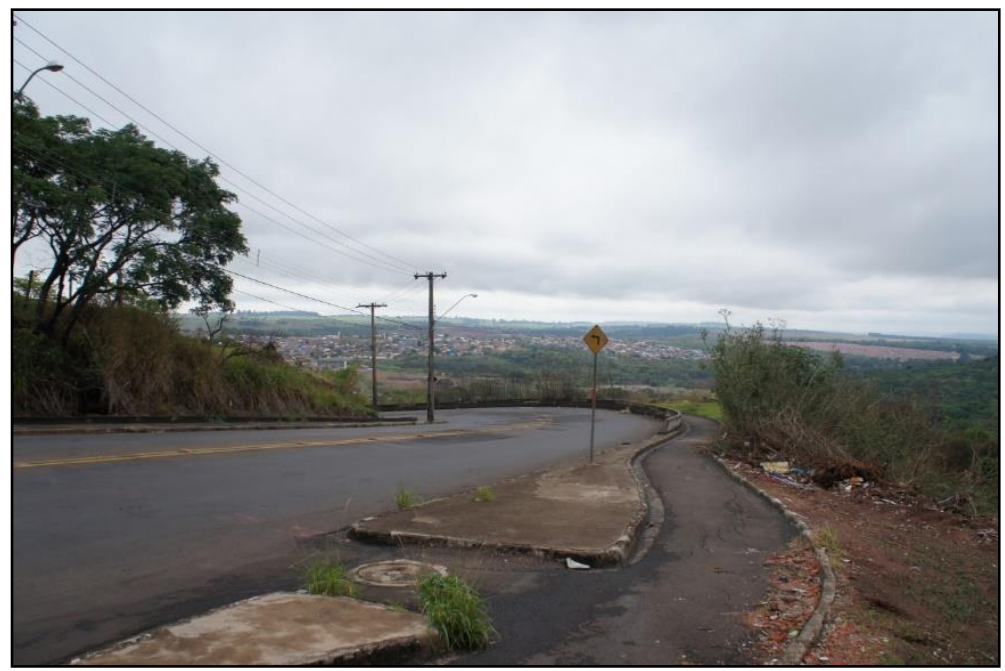

FOTO 1: AVENIDA INTEGRAÇÃO (LIGAÇÃO ENTRE OS BAIRROS JARDIM CRUZEIRO DO SUL E O BAIRRO JARDIM ARACY.

A Foto 1 ilustra a Avenida Integração e a confluência entre os dois bairros. Essa via é a única ligação entre o centro da cidade e os bairros, todas as linhas de ônibus circulam nesse eixo viário. Devido ao grande número de moradores no Bairro, dinâmica reforçada por aqueles que foram contemplados com o projeto "Minha Casa, Minha Vida", faz-se necessário um planejamento da mobilidade e que haja a troca de informações para a busca de um planejamento integrado entre as Secretarias de Transporte e Trânsito e aquela de Habitação para superar esse efeito barreira e atribuir maior acessibilidade aos citadinos que habitam ou se deslocam para esse bairro. 


\section{O efeito barreira em Londrina, Estado do Paraná}

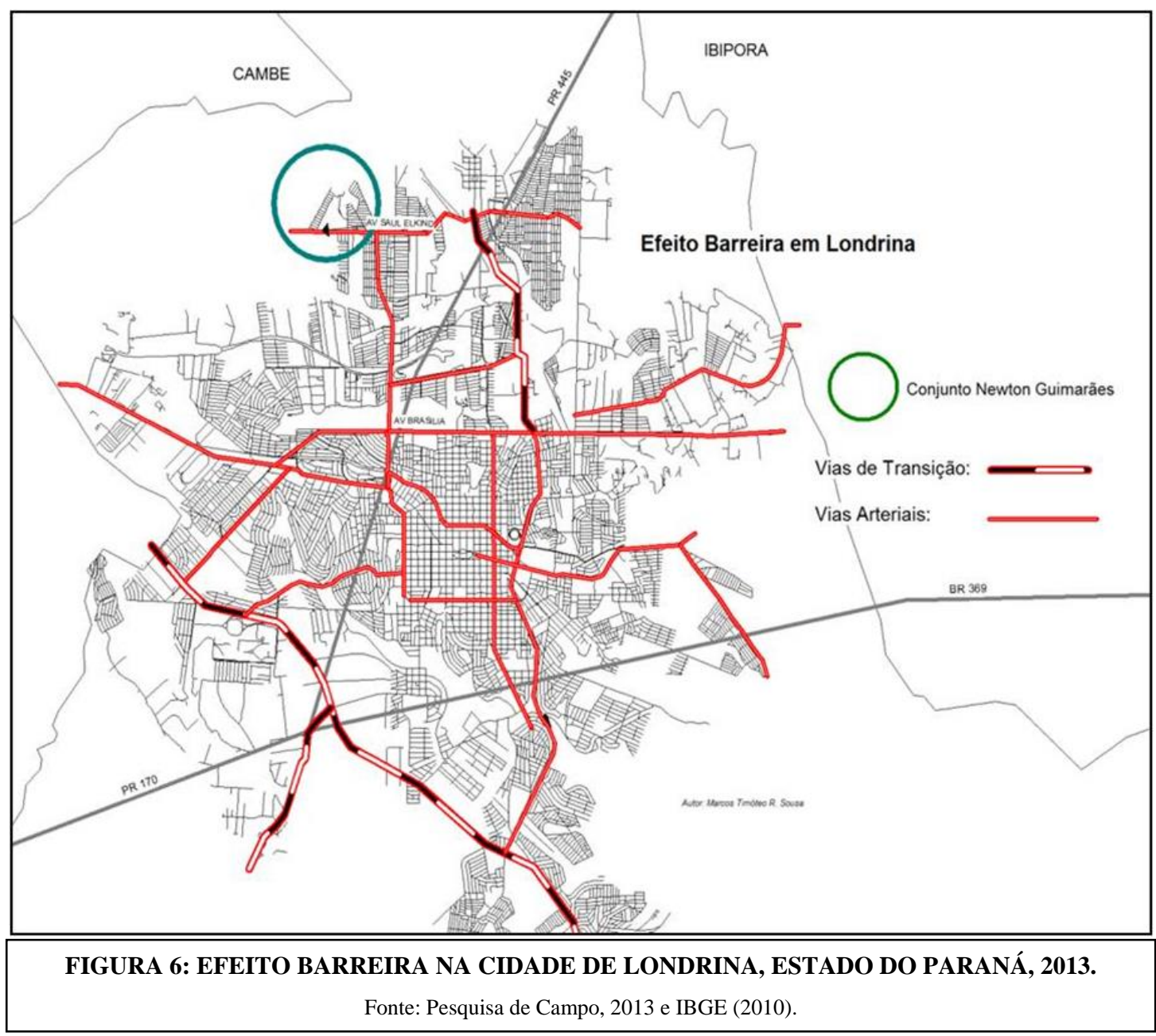

O Conjunto Habitacional Newton Guimarães em Londrina, localizado na zona Norte do município, distancia-se do centro da cidade em 11 quilômetros. O principal eixo viário da zona Norte é a Avenida Saul Elkind, ela corta vários bairros no sentido leste-oeste. Outra via principal que corta o setor no mesmo sentido é a Avenida Brasília. Essas duas grandes avenidas se transformam em uma barreira física para os moradores do Conjunto Habitacional. Entre as duas avenidas há um desnível no terreno, o relevo cria outra barreira na Zona Norte em relação ao centro da cidade. O fundo de vale entre as duas avenidas é a barreira que separa a área central do denominado Bairro "Cincão", que são cinco conjuntos habitacionais da Zona Norte - conforme indicado logo a seguir na Figura 6.

As avenidas Duque de Caxias e Winston Churchil/Rio Branco são os eixos das linhas de ônibus. Todos os itinerários de transporte coletivo para a Zona Norte passam por esses dois eixos. O Conjunto Newton Guimarães é um dos últimos bairros do município, fazendo 
fronteira com a cidade de Cambé, limite do perímetro urbano.

\section{CONSIDERAÇÕES}

O fenômeno da periferização, tendência muito contemplada em grandes cidades, ocorre também nas cidades médias. Com a periferização houve a mobilidade populacional dos moradores das periferias em direção aos centros urbanos, conhecida também como movimentos pendulares, intensificando-se pela lógica de localização de conjuntos habitacionais populosos em áreas suburbanas.

$\mathrm{O}$ formato das cidades, que se estende dos centros às periferias, gerou um empecilho aos moradores de áreas suburbanas, pois as linhas de ônibus tendem a percorrer itinerários mais longos. O espraiamento das cidades, com o uso de grandes vias radiais, gerou obstáculos e ocasionou maior tempo de viagem, sendo esse um dos principais fatores do efeito barreira. A acessibilidade às localidades centrais ficou prejudicada devido aos meandros que as pessoas tendem a percorrer, seja com o uso de transportes coletivos ou individuais.

No processo de formação e estruturação das cidades médias estudadas, assim como dos seus bairros periféricos de baixa renda, ocorreram, na maioria dos casos, em áreas degradadas dos municípios que estão, normalmente, em sua área lindeira e possuem uma barreira física que surge por um processo de formação das cidades. Nesse sentido, reiteramos o destaque para ao menos dois tipos de barreiras físicas: aquelas vinculadas ao processo de ocupação do sítio e aquelas quanto ao modo de estruturação das vias, notadamente, as rodovias.

Para o efeito barreira associado à ocupação do sítio podemos indicar o caso da cidade de São José do Rio Preto que, pela sua formação vinculada ao Rio Preto, divide a cidade, assim como, algumas rodovias que cortam o município desempenham o mesmo papel. Contudo, é o Rio Preto que se destaca pelo efeito barreira na medida em que dificulta a mobilidade e acessibilidade dos moradores das Zonas Norte e Leste do município às áreas centrais. Um segundo caso é aquele da cidade de São Carlos que pode ser verificado pela ocupação de um sítio em que há grande declividade - "Serrinha do Aracy" - e separa dois bairros entre si e, por conseguinte, dificulta o acesso de seus moradores as áreas centrais da cidade.

O efeito barreira associado ao modo de estruturação das vias, notadamente, as rodovias, ocorrem nos municípios de Marília, Presidente Prudente, Ribeirão Preto e Londrina. 
Isso ocorre devido à estruturação histórica, econômica e social dessas cidades. De modo geral, essas cidades se originam vinculadas as atividades econômicas cujos produtos são transportados pelas ferrovias. Os centros dessas cidades estão próximos às estações ferroviárias. As rodovias surgem num outro momento histórico de ampliação da rede urbana e, normalmente, estão distantes do centro das cidades. Os bairros em que as rodovias são uma forma de barreira física ocorreram quando houve a ocupação do sítio além da rodovia e distantes dos centros das cidades.

Tanto num caso como no outro, ou seja, o efeito barreira associado ao modo de estruturação das vias ou aquele associado ao sítio, indica que a formação da barreira física gera dificuldades de mobilidade aos moradores dos bairros periféricos. A barreira física transforma-se numa barreira social pela escassa acessibilidade das cidades as áreas centrais das cidades estudadas.

\section{REFERÊNCIAS}

CARDOSO, Leandro, LOBO, Carlos Fernando Ferreira. Mobilidade espacial da população na Região Metropolitana de Belo Horizonte: análises da acessibilidade com base no censo demográfico de 2010. ANTP, Revista de Transportes Públicos, n. 135, ano 36, $3^{\circ}$ quadrimestre, 2013, p. 21 a 40

CONSIGLIERI, Victor. A morfologia da arquitetura 1920-1970. Lisboa: Companhia Editora do Minho, 1999.

CUNHA, José Marcos Pinto da; JAKOB, Alberto Augusto Eichman; JIMENEZ, Maren Andrea. Expansão Metropolitana, Mobilidade Espacial e Segregação nos anos 90: o caso da RM de Campinas. Salvador, XI Encontro Nacional da ANPUR, 2005.

CORTELETTI, Laís, RIBEIRO, Bárbara Maria Giaccom. Análise do impacto da implantação do trem metropolitano na configuração espacial da cidade. Belo Horizonte: XVI ENAPUR, 2015.

DEL RIO, Vicente. Introdução ao desenho urbano no processo do planejamento. São Paulo: Pini, 1990.

FERRAZ, Antonio Clovis Pinto. Sobre a eficiência e a eficácia do transporte público nas cidades médias e pequenas. Escola de Engenharia de São Carlos, USP. São Carlos, 1990. 
FRANSCISCO, Arlete Maria. Arquitetura e cidade: habitação vertical em São José do Rio Preto. São Paulo, Dissertação de Mestrado, FAU-USP, 2008, p.227.

LYNCH, Kevin. A Imagem da Cidade. Tradução Jéferson Luiz Camargo. São Paulo: Martins Fontes, 1997.

MOUETTE, Dominique. Os pedestres e o efeito barreira. São Paulo, Tese de Doutorado, POLI/USP, 1998.

OKAMOTO, Jun. Percepção ambiental e comportamento: visão holística da percepção ambiental na arquitetura e na comunicação. São Paulo: Mackenzie, 2002.

RODRIGUES, Maurício Olbrick. Avaliação da qualidade do transporte coletivo da cidade de São Carlos. Dissertação de Mestrado, São Carlos, USP, 2006.

SANCHES, Sueli Penha. Acessibilidade: um indicador do desempenho dos sistemas de transporte nas cidades. Anais do X Congresso de Pesquisa e Ensino em Transporte, vol.2, p.199-208, 1996.

SANTANNA, João. A. Uma avaliação da influencia da acessibilidade no valor de terrenos urbanos ociosos. Monografia. São Carlos, UFSCar, 1995.

SOBARZO MINO, Oscar Alfredo. Os espaços da sociabilidade segmentada: a produção do espaço público em Presidente Prudente. Presidente Prudente, Tese de Doutorado, FCT/Unesp Presidente Prudente, 221 p., 2004.

SPOSITO, Maria Encarnação Beltrão. Lógicas econômicas e práticas espaciais contemporâneas: cidades médias e consumo. 2011, 43f. Projeto Temático FAPESP (Geografia) - Universidade Estadual Paulista, Faculdade de Ciências e Tecnologia, Presidente Prudente.

ULIAN, Flávia. Crise da Mobilidade Urbana na Cidade de São Paulo. Belo Horizonte: Percurso Acadêmico, v.3, n.6, 2013.

VASCONCELOS, Eduardo Alcântara. Transporte urbano nos países em desenvolvimento: reflexões e propostas. São Paulo: Annablume, 2000. 